\title{
Effective Laparoscopic Management Lymph Node Dissection for Gallbladder Cancer
}

\author{
Eduardo A. Vega, $\mathrm{MD}^{1}$, Suguru Yamashita, MD, $\mathrm{PhD}^{1}$, Yun Shin Chun, $\mathrm{MD}^{1}$, Michael Kim, $\mathrm{MD}^{\mathbf{1}}$,

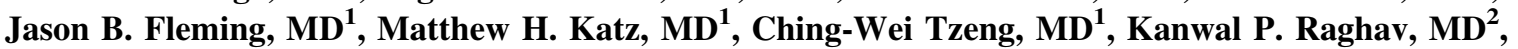 \\ Jean-Nicolas Vauthey, $\mathrm{MD}^{1}$, Jeffrey E. Lee, $\mathrm{MD}^{1}$, and Claudius Conrad, MD, PhD $^{1}$ \\ ${ }^{1}$ Department of Surgical Oncology, The University of Texas MD Anderson Cancer Center, Houston, TX; ${ }^{2}$ Department of \\ Gastrointestinal Medical Oncology, The University of Texas MD Anderson Cancer Center, Houston, TX
}

\begin{abstract}
Background. Part of optimal prognostication of gallbladder cancer is optimal lymph node staging. ${ }^{1,2}$ Accurate laparoscopic lymph node staging is dependent on a systematic approach to sampling N1 and N2 lymph node stations. ${ }^{3}$ Stations with the highest risk of involvement are $12 \mathrm{a}, \mathrm{b}, \mathrm{p}$ and c, 13 and 16 , as well as 8 and $9 .^{4}$

Patient. A 59-year-old man underwent stem cell transplantation for acute myeloid leukemia. Thirty-nine days later he developed acute cholecystitis, which was managed with a cholecystostomy tube. Two months later, a laparoscopic cholecystectomy was performed where a $\mathrm{T} 2$ well- to moderately-differentiated gallbladder cancer was detected, along with an uninvolved lymph node in station $12 \mathrm{c}$, and cystic duct stump negative for cancer.

Technique. With the patient in the French position, wide kocherization allowed for sampling of lymph node stations 13 (retropancreatic) and 16 (aortocaval). Thereafter, a portal lymphadenectomy of stations 12a, b, c and p was performed. A partial resection of segments $4 \mathrm{~b}$ and 5 , as well as sampling of the cystic duct stump, completed the procedure.

Conclusion. Accurate prognostication is one of the major goals of oncologic re-resection of incidentally discovered gallbladder cancer. This can be achieved via a systematic
\end{abstract}

Electronic supplementary material The online version of this article (doi:10.1245/s10434-017-5773-y) contains supplementary material, which is available to authorized users.

(C) Society of Surgical Oncology 2017

First Received: 4 November 2016;

Published Online: 6 February 2017

C. Conrad, MD, $\mathrm{PhD}$

e-mail: cconrad1@mdanderson.org and complete dissection of portal, aortocaval and retropancreatic lymph node stations. Targeting of stations 16 and 13 requires wide kocherization, and complete portal lymphadenectomy of stations $12 \mathrm{a}, \mathrm{c}, \mathrm{p}$, and b necessitates safe, minimally invasive dissection of the hepatoduodenal ligament.

DISCLOSURES Eduardo A. Vega, Suguru Yamashita, Yun Shin Chun, Michael Kim, Jason B. Fleming, Matthew H. Katz, Ching-Wei Tzeng, Kanwal P. Raghav, Jean-Nicolas Vauthey, Jeffrey E. Lee, and Claudius Conrad have declared no conflicts of interest.

\section{REFERENCES}

1. Shindoh J, de Aretxabala X, Aloia TA, Roa JC, Roa I, Zimmitti G, et al. Tumor location is a strong predictor of tumor progression and survival in T2 gallbladder cancer: an international multicenter study. Ann Surg. 2015;261(4):733-9.

2. Yamashita S, Passot G, Aloia TA, Chun YS, Javle M, Lee JE, et al. Prognostic value of CA19-9 normalization in patients undergoing resection of biliary tract cancer. Br J Surg. 2017. doi: 10.1002/bjs. 10415.

3. Kokudo N, Makuuchi M, Natori T, Sakamoto Y, Yamamoto J, Seki M, et al. Strategies for surgical treatment of gallbladder carcinoma based on information available before resection. Arch Surg. 2003;138(7):741-50.

4. Yamashita S, Loyer E, Chun YS, Javle M, Lee JE, Vauthey JN, et al. Laparoscopic management of gallbladder cancer: a stepwise approach. Ann Surg Oncol. 2016;5(23 Suppl):892-3. 